
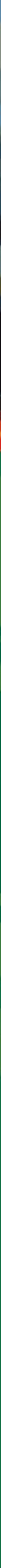


\title{
1 \\ What is this thing called 'community'?: An example in far north Queensland
}

\begin{abstract}
Alison Cottrell
The Bloomfield River region lies in tropical north Queensland, Australia (see Figure 1.1). It is a mountainous area adjacent to the coast and bordered by the Wet Tropics World Heritage Area. The catchment is vulnerable to flooding, bushfires and tropical cyclones. In the process of conducting an appraisal of community awareness and preparedness for natural hazards (Cottrell et al., 2001), it became apparent that it was necessary to ask the question: what is a community, and what are the implications for hazard studies and practice?
\end{abstract}

The people who live in the Bloomfield River region are a mix of indigenous and non-indigenous residents estimated to amount to approximately 2,000 people, depending on the time of the year. Most income is from social security payments and government employment. There is an Aboriginal community at Wujal Wujal; cattle properties; tourist ventures which range from inexpensive camping to the very expensive; 'eco-tourism' resorts; people who have retired on independent incomes; those working for the public sector; and those who have 'opted out' of mainstream living, some of whom hold very strong views about conservation. Major industries include retail, tourism, grazing and horticulture.

\section{The Bloomfield River Region}

The Bloomfield River region is the traditional country of the Kuku-Yalangi people. Many of the people have homes in the township area of Wujal Wujal, the township of Ayton and/or have seasonal camps in other parts of the region or live on outstations in the region. The diversity of the Aboriginal residents at Bloomfield was documented by Anderson (1984), and appears to have maintained its diversity. In particular there are two main families of political significance, between whom governance of the Aboriginal community fluctuates. 

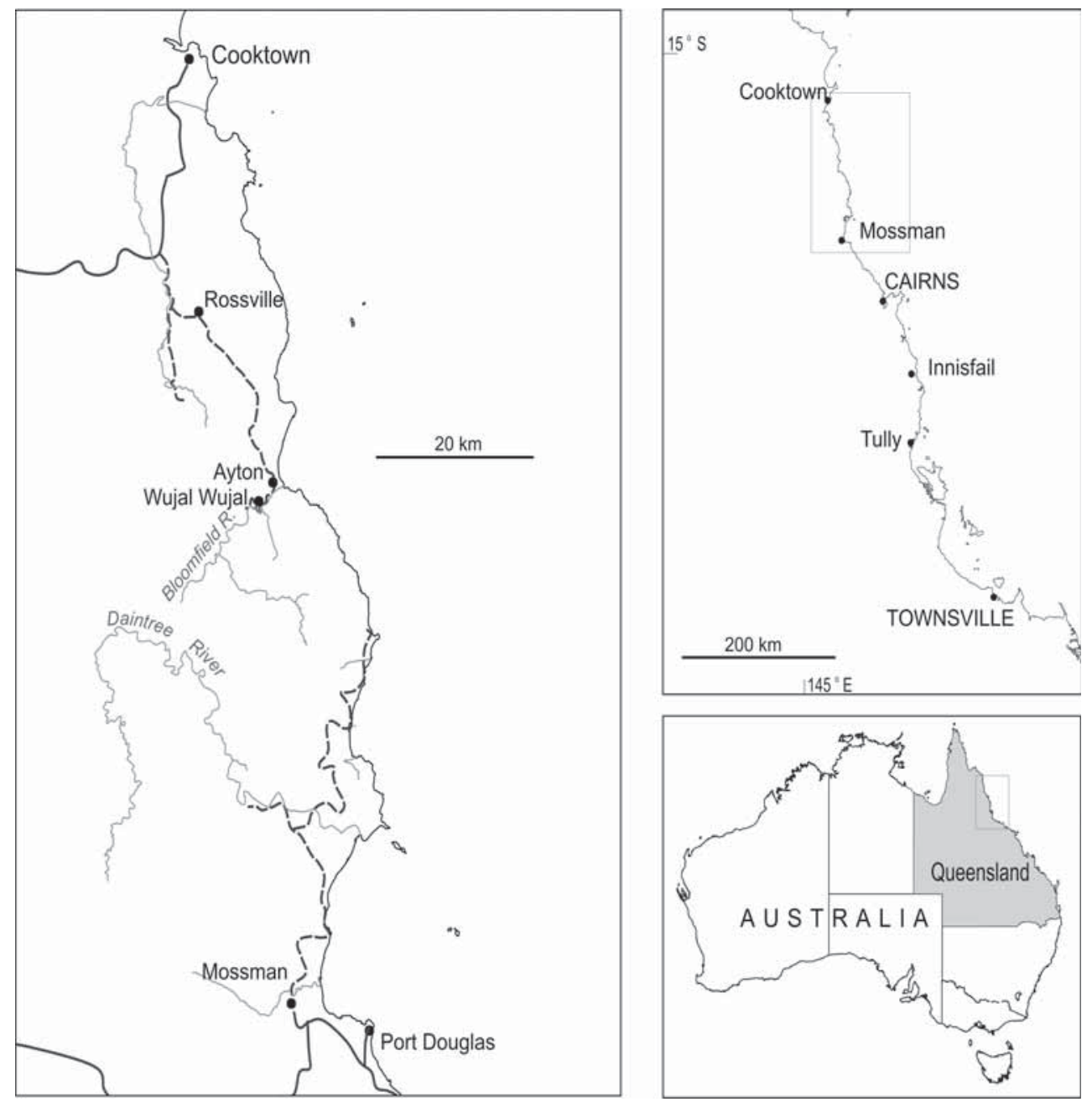

Figure 1.1 The Bloomfield River region, Queensland, Australia

The remainder of the residents in the region have a variable, but in some cases lengthy, history (Anderson, 1983) depending on the sector with which they are involved. For example, there are some families associated with grazing who have been there for several generations. There are also those who have had tourism related businesses for a decade or more. Some people came with the establishment of hippy colonies in the 1970s, bought properties and stayed. More recently, a number of retirees have settled, as well as a group the locals referred to as 'ferals' who live in makeshift 
dwellings in the forest areas. ${ }^{1}$ There are also an unpredictable, and unmonitored, number of tourists who move through the area.

Leaving aside the issue of tourists, there appears to be quite a lot of mobility in the region. Residents regularly travel to Cairns or Cooktown to shop, seek medical and other professional services, board at schools and visit relatives, be they Aboriginal or non Aboriginal.

There are three local governments involved in the region. The area physically covered by the Wujal Wujal Aboriginal Shire Council is that area relating to what was previously a mission and then a Deed of Grant in Trust (DOGIT) community. The social responsibility of this council extends beyond the physical boundaries to meet the needs of the Aboriginal community in the broader region. Cook Shire is technically responsible for the residents to the north of the Bloomfield River and has a local representative who reports to the council in Cooktown. The Douglas Shire, which is based in Mossman, is responsible for the residents south of the Bloomfield River but has no local representative. While there is a sealed road from Mossman through the tourist destination Daintree region, this terminates at Cape Tribulation, after which an unsealed motor-able track traverses the next 30 to 40 kilometres through the Daintree National Park. Environmentalists have campaigned vigorously for the closure of this road, and subsequently due to lower levels of maintenance it is impassable for extensive periods of the wet season. This and the lower level of political support from Douglas Shire led to feelings that residents north of the river were better served than those to the south. However, networks of relationships appear to readily cross the river.

There are a number of community groups operating in the area, some of which are highly active in community development and planning: the Bloomfield/Yalangi Catchment Committee (representing 26 interest groups); the Bloomfield River District Residents Association; the Bloomfield Sports Association; the Bloomfield River District Residents Association; a State Emergency Services (SES) group being established to be based at Wujal Wujal but involving the whole catchment; a well-established health centre is located at Wujal Wujal and serves the whole region; and a Home and Community Care group servicing the needs of the elderly and those with disabilities at Wujal Wujal and Ayton; There is a Community Economic Development Program (CEDP) at Wujal Wujal and Rossville, and a District Citizens Association at Bloomfield River.

\footnotetext{
1 Interestingly, there is a component of retired hippies who refer to young people who have opted for the simple lifestyle as 'ferals'. This would make an interesting research topic as to whether this relates merely to length of residence, or to ownership of property vis a vis Hall, Thorns and Willmott, (1984),

Community class and kinship - bases for collective action within localities.
} 
The people who live in the region are quite diverse. Those who have moved into the area have done so for a variety of reasons, sometimes leading to conflicts in aspirations for the region. For example, many of the retirees have aspirations for greater access to infrastructure and services, there are also those with strong conservation values, and the Aboriginal community has a desire for increased services while maintaining traditional control. It is clear then, that there is variation in the level of horizontal integration between and within segments of the community. As well, the level of vertical integration is also varied (Warren, 1963; Martinez-Brawley, 1990). For example, representatives and administrators for the Wujal Wujal Council have strong linkages to other levels of government and services and many members of the non-Aboriginal community use the Internet extensively as well as having linkages to government agencies and other support networks.

The fact that the area becomes isolated so quickly in the wet season, combined with the fact that three local government bodies are required to act to meet community needs and do so to varying degrees essentially means that the community is left to deal with its problems on its own. This raises the issue of community based disaster or hazard response planning, and consequently, coming to grips with the issue of what is a community, and what are the implications for hazard studies and practice? This question needs to be addressed because there seems to be an assumption that rural and/or remote communities approach the ideal 'gemeinschaft' (i.e. community) (Cahnman \& Heberle, 1971). However, from the above description it is clear that in the Bloomfield River region, this may not be an accurate description.

\section{Defining Community}

To some extent the issue of defining community in Australia, in the context of hazards, has been addressed by Marsh and Buckle (2001), Buckle (1999) and Sullivan (2003). The discussion centred on the two issues of the complexity of community and the need to be clear about defining community. However, it is not merely the defining of community that is the issue here, but also whether it is ideology that is being discussed. It is important to move the discussion forward by elaborating on how the ideas/definitions/theories of community have developed over time. A detailed discussion of the diversity of perceptions of community within sociology is covered by Bell and Newby (1971) who built on Hillery's (1955) analysis of community definitions. Although Hillery was pessimistic about clarity because of the 94 definitions identified, Bell and Newby built on that analysis to find some common threads (see Table 1.1 below). They conclude that a "majority of definitions include, in increasing importance for each element, the following components of community: area, common ties and 
social interaction" (Bell \& Newby, 1971, p. 29). They then proceed to introduce the notion that conceptualising community as networks may be a productive strategy. This view of community is pursued with great vigour by Wellman $(1988,2001)$.

Wellman (1988) argues that the evidence that communities exist beyond location is clearly apparent. Wellman also suggests that by focussing on community as network allows the endurance of social relationships to be evidenced and that conceptualising community as networks allows linkages between small and large scale phenomena in a seamless manner.

Table 1.1 A classification of selected definitions of community (after Hillery)

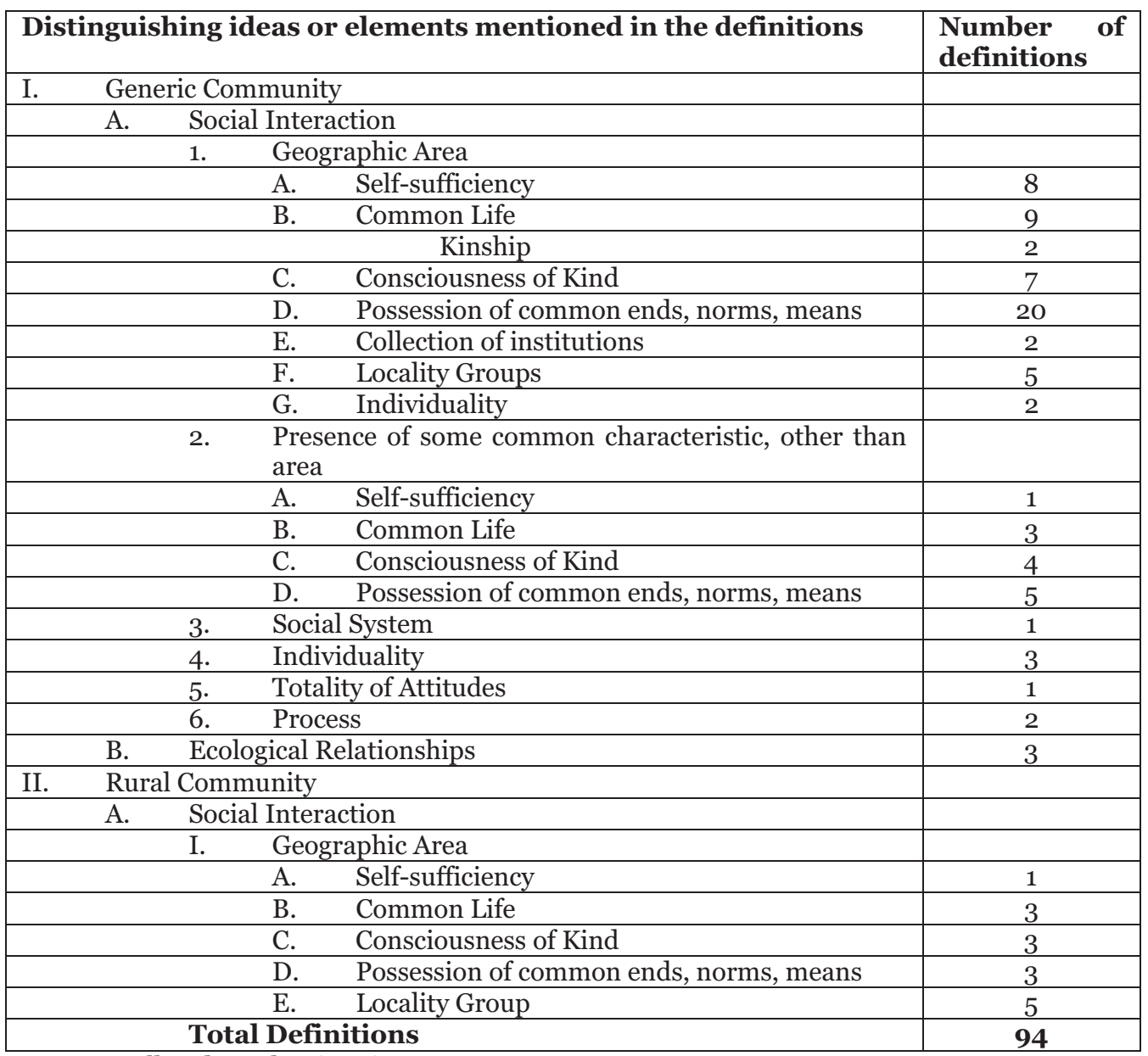

Source: Bell and Newby, (1971), pp. 28-29 


\section{History of Ideas about Community}

Nisbet (1970), Bell and Newby (1971) and Wellman (1988) all remind us of the long history of intellectual traditions which inform our debates about what is community. For Nisbet, there is a 'rediscovery of community' in the nineteenth century. Nisbet identified the nineteenth century concerns with community as a reaction to the concept of contract, rationalism and modernism of the sixteenth to eighteenth centuries (which in itself was a reaction to community as embedded in feudal relations). It is not unusual in social theory to find that at any point in time there are various views held about social phenomena, but that at a particular point in time certain approaches/views dominate. In the $19^{\text {th }}$ century various levels of scale are used about the notion of community. That is community as nation, community as town or city, community as a geographical location. These remain with us, as do strong feelings about what constitutes community, for example Nisbet states:

By community I mean something that goes far beyond mere local community. The word, as we find it in much nineteenth- and twentieth-century thought encompasses all forms of relationship which are characterized by a high degree of personal intimacy, emotional depth, moral commitment, social cohesion, and continuity in time. Community is founded on man (sic) conceived in his wholeness rather than in one or another of the roles, taken separately, that he may hold in a social order. It draws its psychological strength from levels of motivation deeper than those of mere volition or interest, and it achieves its fulfilment in a submergence of individual will that is not possible in unions of mere convenience or rational assent. Community is a fusion of feeling and thought, of tradition and commitment, of membership and volition. It may be found in, or be given symbolic expression by, locality, religion, nation, race, occupation or crusade. Its archetype, both historically and symbolically is the family, and in almost every type of genuine community the nomenclature of family is prominent. Fundamental to the strength of the bond of community is the real or imagined antithesis formed in the same social setting by the non-communal relations of competition or conflict, utility or contractual assent. These, by their relative impersonality and anonymity, highlight the close personal ties of community (Nisbet, 1970, pp. 47-48).

In Nisbet's (1974) view community is central to sociology: community and conflict in relation to the military, political, religious, revolutionary, ecological, and plural communities are discussed at some length. 
Nisbet (1970) and Bell and Newby (1971) both structure their discussions of community in ways that offer us mechanisms for a clearer understanding of the matter. Both discussions refer to Community as Typology or Types; Community as Methodology or Study Method; and Community a Microcosm, or the Molecular Community. Nisbet (1970) also discusses the Empirical Community and the Moral Community while Bell and Newby (1971) expand on Ecological Approaches; Community as Organisations; and Community, Locality and Network.

For this discussion: types, methods, the empirical and the moral community deserve some attention.

\section{Community as Methodology}

Durkhiem is identified by Nisbet as the key figure in the use of community as a methodology for understanding four major themes in human behaviour: morality; analysis of contract; the study of suicide; and the nature of 'man' (sic) (Nisbet, 1970, pp. 82-97). Bell and Newby (1971) include a series of community studies which illustrate this approach quite extensively.

\section{Community and Typology}

It is difficult to imagine a discussion on 'community' which does not refer to Toennies. Cahnman and Heberle (1971) discuss clearly the influence of the Romantic Period and in particular the influence of Comte and Hobbes on Toennies. It is also apparent that from very early on Toennies had to defend this position with other academics of the time; it was necessary to make it clear the position was not idealising gemeinschaft (community) and demonising gesellschaft (society), as Cahnman and Heberle state:

By "community," the reader must not understand a territorial or administrative entity, but what is held in common, what makes for cohesion, what provides bond among men (sic). Occasionally, the meaning of the word "community" comes near to the one of "communion," as in intimate friendship and similar relations that are beyond question. ... We (the editors) have translated Gesellschaft as "association" rather than as "society, "because in the word "association" the meaning of choice and purpose comes clearly to the fore... (Cahnman \& Heberle, 1971, p. xx).

It is necessary to also view the social relations of both ideal types as having positive and negative characteristics, particularly to avoid the trap of resorting to ideology and rhetoric. 
Toennies clarified this position:

I have not considered it as an "ideal", but as an ideal, or constructional, type. ...I do not know of any condition of culture or society in which elements of Gemeinschaft and elements of Gesellschaft are not simultaneously present, that is, mixed (Cahnman \& Heberle, 1971, pp. 9-10).

Clearly then, Toennies differentiates between heuristic devices and what might be described as 'reality' or praxis. As well, the need for clarification is already apparent. The debate about what constitutes 'community' clearly: "has entertained social scientists for almost as long as there has been societies to study" (Sullivan, 2003, p. 19).

This need to distinguish between heuristic devices and 'reality' brings us clearly to the door of ideology. It also brings to the fore the notion of the moral community which will be discussed later. Whilst the distinction between theory and ideology can sometimes appear blurred, Neuman (1997, pp. 37-38) provides a useful clarification. Cohen (1985) verges on accusing theorists of ideology when examining the dichotomies that were historically present in theories of community. Toennies' gemeinschaft versus gesellschaft; Durkeim's mechanical versus organic solidarity; Redfield's folk versus urban society was another 'imagined entity' (Bell \& Newby, 1971, p. 43) and the Chicago School of urban scholars who dealt with urban development in particular. The dichotomy was extended to include postindustrial society by Richmond to further a developmental view of social relationships with an implication that the more urban and (post) industrial tended to be more sophisticated and have more advanced social relations.

In critiquing these ideal types of simple versus complex, Cohen (1985) identifies three 'myths' about 'community' which seem to prevail: the myths of simplicity, egalitarianism and inevitable conformity. In terms of simplicity, Cohen suggests that there are no simple relationships in any community. In urban communities there may be a greater number of roles encountered by individuals, but even in small societies, relationships are complex. Cohen suggests that in some cases, living in large communities makes it easier to withdraw from difficult situations, particularly if dealing with a stranger. Whereas in a small community, often financial and other activities are conducted by people who are in contact with each other on a regular basis. This regular contact requires much more careful social transactions if amiable relations are to be maintained. In large communities it is possible to have relations conducted with strangers and with people who are contacted on a regular basis. Therefore there are few social relations 
which are 'simple', and face to face, and intimate relations occur in all societies.

Cohen also suggests that egalitarianism should be questioned as to whether it is: "ideology ('we should all be equal here')...rhetoric ('we are all equal here')...and...pragmatism ('we behave as if we were all equal here')..." (Cohen, 1985, p. 33). None of these, Cohen suggests, should be confused with the social reality of egalitarianism.

The myth of inevitable conformity is the view that small scale, isolated communities will become overwhelmed by the dominant culture of the large urban centres and lose any identity they may have had. Cohen suggests that these views: "Assume that people can have their culture stripped away, leaving them quite void, then to be refilled by some imported superculture. They assume, in other words, that people are somehow passive in relation to culture: they receive it, transmit it, but do not create it" (Cohen, 1985, p. 36). Community, Cohen suggests, is a socially constructed, symbolic phenomenon. As social change occurs, social and physical boundaries may be lost, but the symbolic socially constructed boundaries are not lost.

However, this shared sense of community which is symbolic may not have exactly the same meaning for each member of the community. For instance, community members may use similar words to describe their community and its activities, but when pressed to describe what these definitions actually mean to them, differences become apparent.

Similarly, Milofsky (1988) indicates: "Communities and their organizations are hard to study...because they exist primarily in the minds of people. Each member perceives a different community, as roles, geographic location, cultural background, occupation, and a host of other factors vary. 'Community' also has a background factor in the lives of most people" (Milofsky, 1988, p. 4). This brings us to the idea of the moral community.

\section{The Moral community}

Nisbet (1970), in discussing the centrality of the idea of community to sociology, introduces the significance of Comte's views on the notion of the "community lost, community to be gained" (Nisbet, 1970, p. 56). This is a theme well recognised by those who consider the issue of community. Not only do researchers and lay people alike have ideas about what community is, but researchers and lay people may also hold views about the moral worth of community. Again, this can be reflected in those continua of oppositional typologies. Depending on the viewer, urban and complex may be sophisticated and contemporary or the small and simple may be the 'truer' 
community to be valued and preserved or lamented in its passing. Similarly, Wellman (1988) argues:

Contemporary urbanites perversely flatter themselves by remarking how stressful are modern times. They fear that communities have fallen apart, with loneliness and alienation leading to a war of all against all. They are sure that their pre-industrial ancestors led charmed lives when they could bathe in the warmth of true solidarity community...Paradoxically, few urbanites will confess to living lives of lonely desperation. They know they have supportive communities, and that their friends, neighbors, kin and co-workers have them as well....At the same time, nostalgia for the perfect pastoral past dims awareness of the powerful stresses and cleavages that have always pervaded human society (Wellman, 1988, p. 81).

It is the 'loss of community' lament that is most problematic for researchers because some get caught up with what people want community to be, rather than what more objective observations might reveal, that is, what might be described as the empirical community.

\section{The Empirical Community}

For Nisbet (1970) the study of small communities to make what might be described as 'scientific' generalizations about social relations clearly began with Le Play's study of kinship and community in The European Working Classes where he compared 45 families from all over Europe (see also Périer, 1998). Bell and Newby (1971) provide a useful summary of American and European studies of community, with the wry observation that despite the fact there is so much trouble defining community, community studies are none-the-less conducted. The methods used to study communities are varied, but the authors identify some generalizations. Participant observation is one method, but one which despite the richness of the outcome is often criticized for being overly sympathetic to the object of study. Survey techniques may appear attractive for larger population areas, but there is the warning that surveys target individuals not communities, and that unless these are offset with other information could be quite misleading. Researchers are also reminded that there are other forms of data, specifically organisational and other records that might be interrogated to provide information. Above all, Bell and Newby (1971) insist that social interaction is what is sought within the notion of studying community. This by necessity requires identification of organizations and their interactions, class and other status relations which might influence involvement, and power and conflict relations. Bell and Newby also include the use of ecological approaches and network analysis. The merits of network analysis in 
community studies are exemplified particularly in Wellman (1988) and Tindall and Wellman (2001).

\section{Implications for Community studies in the context of Hazards}

Clearly, there is a need to understand in general terms, what is meant when people refer to 'community'. Are they lamenting the 'loss of the (moral) community' in times of high levels of urbanisation, population mobility and social change? If it is an individual speaking, it is important to remember it is their view of what constitutes community which may differ from other views. What are people implying when they talk about community, is it a locality or is it the networks of relationships that occur at that locality? It cannot be assumed that communities are homogenous entities for which planning is easily undertaken. Communities are also not static, geographically, in terms of membership and in terms of ideology or beliefs. In particular researchers should not be concerned with discovering, or wishing to discover, imaginary idealised social structures. When using 'community' as a methodology, however, there can be a danger of developing a series of case studies that are atheoretical.

Some authors suggest there is no such thing as community, or that community has come to be meaningless and that the term should not be used. Bell and Newby (1971) warn against semantic sleights of hand by merely choosing another word. However, it is highly unlikely that in the short term community will be lost from our vocabulary, and as Nisbet (1970) quotes Durkheim: "If the idea of society were extinguished in individual minds, and the beliefs, traditions and aspirations of the group were no longer felt and shared by individuals, society would die. We can say of it what we...said of divinity: it is real only insofar as it has a place in the human consciousness..." (Nisbet, 1970, p. 95). For Wellman (2001) the notion of community is well and truly alive, even in, or perhaps especially because of, the age of the Internet.

\section{Conclusion}

In the context of hazards, and the Bloomfield River region is an example, geographic location remains of importance, because the types of hazards to which people may be exposed are to a large extent determined by location. In the context of the discussion of what might constitute community in the context of hazards, there are some clear conclusions to be made. What was sought was an empirical view of community, that would allow a more effective approach to hazard mitigation. What was found was clearly a location with at least two primary community networks within which social status and power relations figure strongly, and do vary. Within the 
Aboriginal community ${ }^{2}$ there were two politically strong families and within the non-Aboriginal community, a range of networking options, with some people clearly having very little influence. These networks are of prime importance to a situation where hazard planning and mitigation are intended. It can be understood that the networks may be able to provide mutual support in the context of a natural hazard.

It is also clear that because of networks outside the geographical location, resources such as weather information are more readily available than might have been assumed. The benefits of community studies to hazard mitigation and planning clearly remains useful, but it must be acknowledged that each community will be different and that this needs to be understood by service providers.

${ }^{2}$ It is interesting to note the Aboriginal community was referred to as 'community' while the mainstream community was referred to as 'residents', by Aboriginal people and mainstream people alike. 